\title{
Body Composition, Muscle Strength, and Physical Function of Patients with Bethlem Myopathy and Ullrich Congenital Muscular Dystrophy
}

\author{
Maria Teresa Miscione, ${ }^{1}$ Francesca Bruno, ${ }^{2}$ Claudio Ripamonti, ${ }^{3}$ \\ Giuliana Nervuti, ${ }^{4}$ Riccardo Orsini, ${ }_{1}^{1}$ Cesare Faldini, ${ }^{1}$ Massimo Pellegrini, ${ }^{5}$ \\ Daniela Cocchi, ${ }^{2}$ and Luciano Merlini ${ }^{6}$ \\ ${ }^{1}$ Department of Orthopaedics, Istituto Ortopedico Rizzoli, IRCCS, 40136 Bologna, Italy \\ ${ }^{2}$ Department of Statistical Sciences, University of Bologna, 40126 Bologna, Italy \\ ${ }^{3}$ Medicina Generale, Istituto Ortopedico Rizzoli, IRCCS, 40136 Bologna, Italy \\ ${ }^{4}$ Direzione Sanitaria, Istituto Ortopedico Rizzoli, IRCCS, 40136 Bologna, Italy \\ ${ }^{5}$ Department of Public Health Sciences, University of Modena and Reggio Emilia, 41122 Modena, Italy \\ ${ }^{6}$ Laboratory of Musculoskeletal Cell Biology, Istituto Ortopedico Rizzoli, IRCCS, 40136 Bologna, Italy
}

Correspondence should be addressed to Luciano Merlini; luciano.merlini@ior.it

Received 24 June 2013; Accepted 14 August 2013

Academic Editors: Y. K. Hayashi, G. Onder, L. Scorrano, and H. Topaloglu

\begin{abstract}
Copyright (C) 2013 Maria Teresa Miscione et al. This is an open access article distributed under the Creative Commons Attribution License, which permits unrestricted use, distribution, and reproduction in any medium, provided the original work is properly cited.

Objective. To determine the contributions of body mass, adiposity, and muscularity to physical function and muscle strength in adult patients with Bethlem myopathy (BM) and Ullrich congenital muscular dystrophy (UCMD). Materials and Methods. Evaluation involved one UCMD and 7 BM patients. Body composition was determined by body mass index (BMI) and dual-energy-X-rayabsorptiometry (DXA), muscle strength by dynamometry, physical function by the distance walked in 6 minutes (6MWD), forced vital capacity (FVC) by a spirometer. Results. Six participants were of normal weight and 2 overweight based on BMI; all were sarcopenic based on appendicular fat free mass index (AFFMI); and 7 were sarcopenic obese based on AFFMI and \% fat mass. Average muscle strength was reduced below $50 \%$ of normal. The 6MWD was in BM patients $30 \%$ less than normal. FVC was reduced in 4 of the BM patients. Muscle strength had a good correlation with the physical function variables. Correlation between muscle strength and BMI was poor; it was very high with AFFMI. AFFMI was the best single explicator of muscle strength and physical function. Conclusion. Muscle mass determined by DXA explains most of the variability of the measures of muscle strength and physical function in patients with BM and UCMD.
\end{abstract}

\section{Introduction}

Mutations in any of the three genes (COL6A1, COL6A2, and COL6A3) coding for collagen VI, a major extracellular matrix protein of the endomysium of skeletal muscles, cause the collagen VI-related myopathies [1] including Bethlem myopathy (BM), Ullrich congenital muscular dystrophy (UCMD), and the two rarer variants limb girdle and myosclerosis myopathy $[2,3]$. Bethlem myopathy is a congenital or early-onset muscular dystrophy characterized by axial and proximal muscle weakness $[4,5]$, and the hallmark of the disease is the presence of contractures of the interphalangeal joints of the last four fingers [6]. Bethlem myopathy is usually mild, sometimes slowly progressive, with some affected individuals over 50 years of age needing aids for outdoors mobility [7]. Respiratory failure is part of the clinical spectrum and can occur in patients with preserved ambulatory function [8]. UCMD is a severe congenital muscular dystrophy characterized by early onset, generalized and rapidly progressive muscle wasting and weakness, proximal joint contractures, and distal joint hyperflexibility. Independent ambulation is not achieved in the severe cases or is lost during childhood/adolescence in most cases [9-11]. Respiratory failure is early and progressive 
and may require artificial ventilatory support in the first or second decade of life [7].

In the EU, a rare disease is one which affects fewer than 5 people per 10,000 [12]. COL6 myopathies, although probably under diagnosed [13], are very rare disorders with the prevalence estimated as 0.77 per 100,000 for $\mathrm{BM}$ and 0.13 per 100,000 for UCMD [14].

The turning point in basic research on collagen VI myopathies was the discovery that mitochondrial dysfunction mediated by inappropriate opening of the permeability transition pore plays a key role [15-18]; defective autophagy with impaired removal of defective mitochondria amplifies the defect [19]; and reactivation of autophagy with a low-protein diet or treatment with cyclosporine A, the mitochondrial PTP inhibitor, cured $\mathrm{Co} \mathrm{al}^{-/-}$mice [15], hinting at a common target among all beneficial treatments-namely, autophagy $[19,20]$.

From a scientific and clinically relevant standpoint, the identification, measurement, and treatment monitoring of muscular dystrophy using a single easily administered cost effective test or measure is not currently possible [13]. Therefore, in clinical trials the methodological approach should be as comprehensive and multidimensional as possible, possibly evaluating the same aspect of skeletal muscle with different tools/instruments, to obtain confirmatory evaluations to findings [21]. Clinical trials have already involved paediatric patients with UCMD $[17,18]$ and planned for adult patients with collagen type VI myopathies aiming at correcting defective autophagy [22, 23]. Muscular dystrophy is characterized by an interconnected decline in muscle mass, muscle strength, and muscle function. Therefore, it would be mandatory to include a test of all these aspects as the best assessment in clinical trials. The purpose of this study is to determine the relative contributions of body mass, adiposity, and muscularity to measured physical function and muscle strength in adult patients with COL6 related myopathies.

\section{Materials and Methods}

We reviewed the records of our 75 patients with a clinical/ laboratory phenotype compatible with the diagnosis of BM/ UCMD [7]. Forty-four had a definite molecular diagnosis with recognition of a pathogenetic mutation/s in one of the three COL6 genes $[3,24-30]$. Of the 27 patients, aged 18 years or more, 22 had a diagnosis of $\mathrm{BM}, 3$ of myosclerosis myopathy, and 2 of UCMD. Fourteen of these, who have been followed in the previous 12 months, were contacted. 8 patients ( 5 female, 3 male, mean age $31 \pm 9$ ) with collagen type VI related myopathies accepted to be included in this study. The $7 \mathrm{BM}$ patients were ambulatory, while the one with UCMD was never able to walk and was on nocturnal noninvasive ventilation. The study protocol was approved by the institutional ethical committee. All subjects were fully informed and gave their written informed consent.

Body composition was obtained by DXA (Hologic 4500 W; software version 11.2; Hologic, Inc., Waltham, MA). According to the tree-compartment model of body composition the Hologic software provided regional and whole body estimation of lean mass (LM), fat mass (FM), and bone mineral content (BMC). BMC and LM were added to obtain fat free mass (FFM). Appendicular fat free mass (AFFM) represents the sum of both arms and legs [31]. Body mass, FM, FFM, and AFFM were normalized to height 2 as control for skeletal size [32]. Women with appendicular fat free mass index (AFFMI) $<5.45$ and men $<7.26$ were classified as sarcopenic $[31,32]$. BMI, an index of obesity, was derived from body mass measured by DXA to the nearest gram and height measured to the nearest $0.1 \mathrm{~cm}$. We used BMI to categorized participants as obese $(\mathrm{BMI} \geq 30)$, overweight $(25 \leq \mathrm{BMI}<30)$, or normal weight $(\mathrm{BMI}<25)$ [33]. In addition subjects were classified as obese if their percentage body fat derived from DXA was above the 90th percentile of the Italian population [34]. For men, this cutpoint was $30 \%$ body fat; for women, it was $41 \%$ body fat [34]. Maximal isometric strength was assessed using a hand-held dynamometer (Type CT 3001, Citec, C.I.T. Technics BV, Groningen, The Netherlands) [35]. Four muscle groups were examined bilaterally: hand grip, elbow flexors, knee extensors, and knee flexors [36-38]. Each individual muscle group was tested for at least 3 seconds using a "make" test [37]. The maximum force from three attempts was used in analysis. A composite score (megascore) was calculated by summing the maximal force of the 8 tests for each patient $[38,39]$. Forced vital capacity (FVC) was determined with an electronic spirometer, and per cent-predicted values were calculated based on normal published values. A value between $50 \%$ and $70 \%$ was considered moderately reduced; a value less than $50 \%$ was considered severely reduced [8]. The 6 minute walk test (6MWT) was performed in a corridor, and standardized verbal instructions were given every minute. Timed tests include the time to walk $10 \mathrm{~m}$ and to climb 4 steps.

\section{Statistical Analysis}

The very limited sample size suggested using simple linear regression models to determine the separate relative contributions of the various indices. Linear correlation coefficients have, therefore, been computed for various couples of variables with the aim of choosing the variables for simple linear models without intercept. High values of the linear correlation coefficients help in the choice of identifying the variables with potentially similar meaning for choosing both the dependent and the explanatory variables. The separate relative contributions of body mass and muscularity (seen as explanatory variables) to muscle strength, 6MWD, and pulmonary function (i.e., dependent variables) were evaluated via linear-regression models, expressed as $y_{i}=\beta x_{i}+$ $e_{i}$, without intercept. Each $\beta$ coefficient was estimated via ordinary least squares. The values of this coefficient denote the increment/decrement of the dependent variable for a unit increment of each explanatory variable. To evaluate the strength of each simple linear relationship, we used the goodness of fit measure $R^{2}$. Measurable variables are presented as mean $(x) \pm$ standard deviation (SD) and categorical data as number and percentage.

\section{Results}

4.1. Body Composition. 6 participants were of normal weight and 2 were overweight based on BMI, all were sarcopenic 
TABle 1: Body mass, adiposity, and muscularity. Summaries of individual data grouped according to sex.

\begin{tabular}{lcc}
\hline Variable & Women $(n=5)$ & Men $(n=3)$ \\
\hline Total mass $(\mathrm{kg})$ & $66.7 \pm 12.1$ & $66.3 \pm 11.1$ \\
& (range: $45-74)$ & (range: $55-77)$ \\
BMI $\left(\mathrm{kg} / \mathrm{m}^{2}\right)$ & $22.9 \pm 4.2$ & $22.3 \pm 3.6$ \\
& (range: $18-29)$ & (range: $18-26)$ \\
$\%$ FM & $51.6 \pm 6.6$ & $34.6 \pm 14.2$ \\
& (range: $41-59)$ & (range: $18-44)$ \\
FMI $\left(\mathrm{kg} / \mathrm{m}^{2}\right)$ & $12.0 \pm 3.6$ & $8.0 \pm 4.0$ \\
& $($ range: $7-17)$ & $($ range: $3-11)$ \\
FFMI $\left(\mathrm{kg} / \mathrm{m}^{2}\right)$ & $10.9 \pm 0.8$ & $14.3 \pm 1.3$ \\
& $($ range: $10-12)$ & (range: $13-15)$ \\
AFFMI $\left(\mathrm{kg} / \mathrm{m}^{2}\right)$ & $4.2 \pm 0.8$ & $5.8 \pm 0.6$ \\
& (range: $3-5)$ & (range: $5-6)$ \\
\hline
\end{tabular}

BMI: body mass index, FM: fat mass, FMI: fat mass index, FFMI: fat free mass index, AFFMI: appendicular fat free mass index.

based on AFFMI, and 7 were sarcopenic obese based on AFFMI and \% fat mass (Table 1). FFMI was well below the 5th percentile for all the patients as compared to the normal age related population and also to the $70-80$-year-olds [34]. The sex differences in body composition were as expected, with women having similar BMI but significantly greater adiposity and less muscularity than men.

4.2. Muscle Strength and Physical Function. Muscle strength (Table 2) was reduced in all muscle groups compared with the normative values $[35,40]$. In particular, knee extension and elbow flexion were the weakest compared with healthy subjects in which knee extension exceeds in all $250 \mathrm{~N}$, and elbow flexion exceed $150 \mathrm{~N}$ in women and $250 \mathrm{~N}$ in men $[35,40]$.

The mean 6MWD was in the 7 walkers $415 \pm 71 \mathrm{~m}(418 \pm$ $38 \mathrm{~m}$ in women and $411 \pm 105 \mathrm{in}$ men) as compared to $593 \pm$ 57 and $638 \pm 44$, respectively, in women and men healthy Italian subjects in the same age range [41]. In BM patients $\% \mathrm{FVC}$ was moderately $(<70 \%)$ reduced in three and severely reduced $(<50 \%)$ in one. The UCMD patient with a FVC of $14 \%$ was on mechanical ventilation.

4.3. Correlation between Body Composition, Muscle Strength and Physical Function. All the muscle strength measures had a good correlation with the physical function variables (Table 3). The megascore, in particular, showed very good linear correlation with all the physical function variables $(0.72-$ $0.92)$, stressing its value of muscular strength synthesis. The single measures of physical strength exhibited more variable values (0.38-0.96). Hand grip, in addition to being an important component of megascore and the most easy to perform and repeatable test, had a very strong linear correlation with FVC and \%FVC ( $r=0.96$ and $r=0.89$, resp.).

The linear correlation coefficients between couples of possible explicative variables of body mass and muscularity were different. Highest values, oscillating between 0.95 and 0.98 , occurred between all measures (FFM, FFMI, AFFM, and AFFMI) derived by DXA but were very low between BMI and all these DXA measures of muscularity $(0.08-0.17)$.
TABLE 2: Muscle strength and measured physical function. Summaries of individual data grouped according to sex.

\begin{tabular}{|c|c|c|}
\hline Variable & Women $(n=5)$ & $\operatorname{Men}(n=3)$ \\
\hline Hand grip (N) & $\begin{array}{c}47.3 \pm 18.8 \\
\text { (range: } 12-73 \text { ) }\end{array}$ & $\begin{array}{c}99.0 \pm 22.8 \\
\text { (range: } 67-119 \text { ) }\end{array}$ \\
\hline Elbow flexion $(\mathrm{N})$ & $\begin{array}{c}38.8 \pm 13.7 \\
\text { (range: } 10-52 \text { ) }\end{array}$ & $\begin{array}{c}99.3 \pm 25.0 \\
\text { (range: } 59-133 \text { ) }\end{array}$ \\
\hline Knee extension $(\mathrm{N})$ & $\begin{array}{c}76.2 \pm 38.2 \\
\text { (range: } 24-136)\end{array}$ & $\begin{array}{c}126.3 \pm 77.6 \\
\text { (range: } 50-225 \text { ) }\end{array}$ \\
\hline Knee flexion (N) & $\begin{array}{c}76.7 \pm 31.5 \\
\text { (range: 18-107) }\end{array}$ & $\begin{array}{c}123.0 \pm 55.4 \\
\text { (range: } 54-185 \text { ) }\end{array}$ \\
\hline Megascore (N) & $\begin{array}{c}478 \pm 199 \\
\text { (range: } 160-680 \text { ) }\end{array}$ & $\begin{array}{c}895 \pm 286 \\
\text { (range: } 651-1210)\end{array}$ \\
\hline $10 \mathrm{~m}(1 / T)$ & $\begin{array}{c}0.11 \pm 0.07 \\
\text { (range: } 0-0.17 \text { ) }\end{array}$ & $\begin{array}{c}0.13 \pm 0.04 \\
\text { (range: } 0.09-0.18)\end{array}$ \\
\hline 4 steps $(1 / T)$ & $\begin{array}{c}0.14 \pm 0.09 \\
\text { (range: } 0-0.22 \text { ) }\end{array}$ & $\begin{array}{c}0.24 \pm 0.09 \\
\text { (range: } 0.17-0.33 \text { ) }\end{array}$ \\
\hline 6MWD (m) & $\begin{array}{c}335 \pm 190.2 \\
\text { (range: } 0-458)\end{array}$ & $\begin{array}{c}411 \pm 104.5 \\
\text { (range: } 320-525 \text { ) }\end{array}$ \\
\hline $\mathrm{FVC}(\mathrm{mL})$ & $\begin{array}{c}1788 \pm 863 \\
\text { (range: } 460-2670)\end{array}$ & $\begin{array}{c}3687 \pm 832 \\
(\text { range: } 2760-4370)\end{array}$ \\
\hline$\% \mathrm{FVC}$ & $\begin{array}{c}49 \pm 23.0 \\
\text { (range: } 14-72 \text { ) }\end{array}$ & $\begin{array}{c}73.0 \pm 17.3 \\
\text { (range: } 53-84 \text { ) }\end{array}$ \\
\hline
\end{tabular}

N: Newton, $T$ : time, 6MWD: 6 minute walking distance, FVC: forced vital capacity.

TABLE 3: Linear correlation coefficients between muscle strength (lines) and physical function (columns) variables.

\begin{tabular}{lccccc}
\hline & 6MWD $(\mathrm{m})$ & $\begin{array}{c}10 \mathrm{~m} \\
(1 / T)\end{array}$ & $\begin{array}{c}4 \text { steps } \\
(1 / T)\end{array}$ & $\begin{array}{c}\text { FVC } \\
(\mathrm{mL})\end{array}$ & \% FVC \\
\hline Megascore (N) & 0.74 & 0.72 & 0.92 & 0.89 & 0.78 \\
Hand grip (N) & 0.62 & 0.58 & 0.77 & 0.96 & 0.89 \\
Elbow flexion (N) & 0.45 & 0.38 & 0.62 & 0.94 & 0.81 \\
Knee extension (N) & 0.66 & 0.65 & 0.82 & 0.62 & 0.53 \\
Knee flexion (N) & 0.77 & 0.80 & 0.90 & 0.67 & 0.59 \\
\hline
\end{tabular}

6MWD: 6 minute walking distance, $T$ : time, FVC: forced vital capacity, N: Newton.

The indices of adiposity, BMI and FMI, had a negative correlation with all the muscle strength and physical function variables; BMI correlation coefficients, in particular, were very low and close to independence (Table 4). On the contrary, the indices of muscularity FFMI and AFFMI showed strong positive values when associated with all the dependent variables (Table 4). The highest values of linear correlation occurred between measures of muscle strength and particularly the megascore and FFMI $(r=0.87)$, and AFFMI ( $r=$ $0.93)$, indicating in this case a strong linear association and not a mere replication of the same information.

Body compositions measures (Table 5), expressed alternatively via BMI and AFFMI, behaved very similarly when proposed as linear explicators of indicators of muscle strength (megascore and hand grip) and physical function (6MWD and \%FVC). BMI was a good linear explicator, with $R^{2}$ values varying from 0.77 to 0.85 ; however, the best single explicator was AFFMI, with $R^{2}$ values varying from 0.90 to 0.93 . 
TABLE 4: Linear correlation coefficients between potential dependent (lines) and explanatory (columns) variables.

\begin{tabular}{lcccc}
\hline & BMI & FMI & FFMI & AFFMI \\
\hline Megascore (N) & -0.06 & -0.49 & 0.87 & 0.93 \\
Hand grip (N) & -0.26 & -0.59 & 0.71 & 0.76 \\
Elbow flexion (N) & -0.10 & -0.46 & 0.74 & 0.76 \\
Knee extension (N) & 0.07 & -0.30 & 0.75 & 0.82 \\
Knee flexion (N) & -0.03 & -0.41 & 0.78 & 0.83 \\
6MWD (m) & -0.13 & -0.32 & 0.41 & 0.52 \\
10 m $(1 / T)$ & -0.26 & -0.44 & 0.40 & 0.49 \\
4 steps $(1 / T)$ & -0.12 & -0.45 & 0.68 & 0.78 \\
FVC (mL) & -0.04 & -0.42 & 0.78 & 0.86 \\
\% FVC & -0.02 & -0.30 & 0.57 & 0.68 \\
\hline
\end{tabular}

BMI: body mass index, FMI: fat mass index, FFMI: fat free mass index, AFFMI: appendicular fat free mass index, N: Newton, 6MWD: 6 minute walking distance, $T$ : time, FVC: forced vital capacity.

TABLE 5: Linear models $\left(y_{i}=\beta x_{i}+e_{i}\right)$ of separate relative contribution of body mass and muscularity to muscle strength and physical function.

\begin{tabular}{lccc}
\hline $\begin{array}{l}\text { Dependent } \\
\text { variables }\end{array}$ & $\begin{array}{l}\text { Predictor } \\
\text { variables }\end{array}$ & $\beta$ & $R^{2}$ \\
\hline Megascore (N) & BMI & 27.22 & 0.81 \\
& AFFMI & 141.05 & 0.94 \\
Hand grip (N) & BMI & 2.82 & 0.77 \\
& AFFMI & 14.64 & 0.91 \\
6MWD (m) & BMI & 15.52 & 0.82 \\
& AFFMI & 77.58 & 0.90 \\
$\%$ FVC & BMI & 2.50 & 0.85 \\
& AFFMI & 12.48 & 0.93 \\
\hline
\end{tabular}

$R^{2}$ : coefficient of determination, 6MWD: 6 minute walking distance, $\mathrm{N}$ : Newton, FVC: forced vital capacity.

\section{Discussion}

The main objective of this study was to measure and correlate body composition, muscle strength, and physical function in a cohort of patients with collagen VI related myopathies.

Body composition was evaluated with BMI and DXA. Body fat was greatly underestimated by BMI that classified only 2 patients as overweight while all but one resulted obese according to their percentage of body fat derived by DXA. In addition, DXA showed that all patients had a great reduction in muscularity both in the total body as indicated by the FFMI and particularly in the limbs with the AFFMI so that all could be classified sarcopenic $[31,32]$. It should be stressed that BMI determinations do not measure body fat directly nor distinguish between fat and lean (nonfat) body mass. In fact, in patients there was no evident linear relationship (correlation coefficients ranging from 0.08 to 0.17 ) between BMI and the measures of muscularity derived by DXA. BMI correlates to direct measures of body fat, such as underwater weighing and DXA for most normal people $[42,43]$. However, DXA, providing whole body and regional estimation of skeletal muscle mass in vivo [44], is particularly relevant for the evaluation of body composition in neuromuscular patients who are undermuscled to body size [45-48].
Muscle strength, measured with a dynamometer, was diffusely reduced with average values less than $50 \%$ of normal in the tests of knee extension, hand grip, and elbow flexion.

All the measures of physical functions were reduced in these patients. The distance walked in 6 minutes was in the $7 \mathrm{BM}$ patients $30 \%$ less than in normal age-matched subjects [41]. \%FVC was reduced in 4 of the $7 \mathrm{BM}$, moderately $(<70 \%)$ in 3 , and severely in one $(<50 \%)$. In a cohort of $43 \mathrm{BM}$ patients, FVC was found moderately reduced in 7 (16\%) and severely reduced in 2 [8]. Our figures further stress the importance to regularly evaluate the respiratory function not only in UCMD but also in BM patients [8, 10, 49].

Muscle strength was positively correlated with the measures of physical function. The megascore showed strong correlation with all the physical functions, respiratory functions (0.78-0.89), time to climb 4 steps (0.92), time to walk $10 \mathrm{~m}$ (0.72), and 6MWD (0.74). A good relationship between motor ability and muscle strength has been found in patients with neuromuscular disorders confirming that loss of function is due to loss of muscle strength [37, 50, 51]. Most myopathies, including collagen VI-related myopathies, are slowly progressive disorders characterized by muscle wasting and weakness that compromise motor and respiratory functions. If a cure is available, it should have a positive effect on muscle strength [13].

The various indices of body composition showed very different correlation with the measures of muscle strength and of physical function. It should be noted that muscle mass is the primary determinant of muscle strength in normal subjects $[52,53]$. This statement was also true in our patients, in whom the indices of muscularity (FFMI and AFFMI) were strongly correlated with muscle strength. AFFMI showed the highest coefficients of correlation with muscle strength (0.76 with hand grip and 0.93 with megascore), 6MWD (0.52), timed tests (0.49 and 0.78$)$, and pulmonary functions $(0.68$ and 0.86). Interestingly, the correlation between AFFMI and $6 \mathrm{MWD}$ was only moderate indicating that the contribution of muscularity explains only $50 \%$ of the performance in the $6 \mathrm{MWD}$. In healthy subjects, it has been shown that age, height, sex, and weight were independent contributors to the $6 \mathrm{MWD}$, thus, explaining up to $66 \%$ of the variability [5456]. Finally, AFFMI was also the best single explicator of the measures of muscle strength and physical function.

\section{Conclusions}

Collagen type VI related myopathies, like most muscular dystrophies, show a wide range of clinical severity that is usually evaluated with the assessment of muscle strength and physical function. The best assessment in clinical trials should be as comprehensive and multidimensional as possible in order to fully explore the interconnected compromise of muscle mass, muscle strength, and function. The evaluation of body composition, in particular of muscle mass with DXA, explaining most of the variability of the measures of muscle strength and physical function, should be included in clinical trials.

\section{Conflict of Interests}

The authors declare that they have no conflict of interests. 


\section{Authors' Contributions}

Maria Teresa Miscione have made substantial contribution to acquisition of data. Francesca Bruno performed the statistical analysis. Claudio Ripamonti carried out the DXA studies and contributed to its interpretation. Giuliana Nervuti participated in the acquisition of data and coordination of the study. Riccardo Orsini contributed to interpretation of data. Cesare Faldini participated in the design of the study. Massimo Pellegrini participated in the design of the study and carried out the anthropometric evaluations. Daniela Cocchi participated in the design of the study and substantially contributed to the statistical analysis and interpretation of data. Luciano Merlini conceived the study, participated in its design and coordination, and helped to draft the paper. All the authors revised the paper critically for important intellectual content and gave final approval. Maria Teresa Miscione and Francesca Bruno contributed equally to this work.

\section{Acknowledgment}

This study was supported by Grant no. GUP11007 (Luciano Merlini) from Telethon, Unione Italiana Lotta alla Distrofia Muscolare (UILDM), Italy.

\section{References}

[1] C. G. Bönnemann, "The collagen VI-related myopathies. Ullrich congenital muscular dystrophy and Bethlem myopathy," Handbook of Clinical Neurology, vol. 101, pp. 81-96, 2011.

[2] P. C. Scacheri, E. M. Gillanders, S. H. Subramony et al., "Novel mutations in collagen VI genes: expansion of the Bethlem myopathy phenotype," Neurology, vol. 58, no. 4, pp. 593-602, 2002.

[3] L. Merlini, E. Martoni, P. Grumati et al., "Autosomal recessive myosclerosis myopathy is a collagen VI disorder," Neurology, vol. 71, no. 16, pp. 1245-1253, 2008.

[4] J. Bethlem and G. K. Van Wijngaarden, "Benign myopathy, with autosomal dominant inheritance: a report on three pedigrees," Brain, vol. 99, no. 1, pp. 91-100, 1976.

[5] G. J. Jöbsis, J. M. Boers, P. G. Barth, and M. De Visser, "Bethlem myopathy: a slowly progressive congenital muscular dystrophy with contractures," Brain, vol. 122, part 4, pp. 649-655, 1999.

[6] L. Merlini, L. Morandi, C. Granata, and A. Ballestrazzi, "Bethlem myopathy: early-onset benign autosomal dominant myopathy with contractures. Description of two new families," Neuromuscular Disorders, vol. 4, no. 5-6, pp. 503-511, 1994.

[7] G. Pepe, E. Bertini, P. Bonaldo et al., "Bethlem myopathy (BETHLEM) and Ullrich scleroatonic muscular dystrophy: 100th ENMC International Workshop, 23-24 November 2001, Naarden, The Netherlands," Neuromuscular Disorders, vol. 12, no. 10, pp. 984-993, 2002.

[8] A. J. Van Der Kooi, W. G. De Voogt, E. Bertini et al., "Cardiac and pulmonary investigations in Bethlem myopathy," Archives of Neurology, vol. 63, no. 11, pp. 1617-1621, 2006.

[9] A. Nadeau, M. Kinali, M. Main et al., "Natural history of Ullrich congenital muscular dystrophy," Neurology, vol. 73, no. 1, pp. 2531, 2009.

[10] L. Briñas, P. Richard, S. Quijano-Roy et al., "Early onset collagen VI myopathies: genetic and clinical correlations," Annals of Neurology, vol. 68, no. 4, pp. 511-520, 2010.
[11] T. Yonekawa, H. Komaki, M. Okada et al., "Rapidly progressive scoliosis and respiratory deterioration in Ullrich congenital muscular dystrophy," Journal of Neurology, Neurosurgery \& Psychiatry, vol. 84, no. 9, pp. 982-988, 2013.

[12] "Health indicators for rare diseases: state of the art and future directions," First Report. June 2008, http://www.eucerd.eu/ ?post_type $=$ document $\& \mathrm{p}=1207$.

[13] L. Merlini and P. Bernardi, "Therapy of collagen VI-related myopathies (Bethlem and Ullrich)," Neurotherapeutics, vol. 5, no. 4, pp. 613-618, 2008.

[14] F. L. M. Norwood, C. Harling, P. F. Chinnery, M. Eagle, K. Bushby, and V. Straub, "Prevalence of genetic muscle disease in Northern England: in-depth analysis of a muscle clinic population," Brain, vol. 132, no. 11, pp. 3175-3186, 2009.

[15] W. A. Irwin, N. Bergamin, P. Sabatelli et al., "Mitochondrial dysfunction and apoptosis in myopathic mice with collagen VI deficiency," Nature Genetics, vol. 35, no. 4, pp. 367-371, 2003.

[16] A. Angelin, T. Tiepolo, P. Sabatelli et al., "Mitochondrial dysfunction in the pathogenesis of Ullrich congenital muscular dystrophy and prospective therapy with cyclosporins," Proceedings of the National Academy of Sciences of the United States of America, vol. 104, no. 3, pp. 991-996, 2007.

[17] L. Merlini, P. Sabatelli, A. Armaroli et al., "Cyclosporine a in Ullrich congenital muscular dystrophy: long-term results," Oxidative Medicine and Cellular Longevity, vol. 2011, Article ID 139194, 10 pages, 2011.

[18] L. Merlini, A. Angelin, T. Tiepolo et al., “Cyclosporin A corrects mitochondrial dysfunction and muscle apoptosis in patients with collagen VI myopathies," Proceedings of the National Academy of Sciences of the United States of America, vol. 105, no. 13, pp. 5225-5229, 2008.

[19] P. Grumati, L. Coletto, P. Sabatelli et al., "Autophagy is defective in collagen VI muscular dystrophies, and its reactivation rescues myofiber degeneration," Nature Medicine, vol. 16, no. 11, pp. 1313-1320, 2010.

[20] A. M. Tolkovsky, “Autophagy thwarts muscle disease," Nature Medicine, vol. 16, no. 11, pp. 1188-1190, 2010.

[21] W. C. Chumlea, M. Cesari, W. J. Evans et al., "Sarcopenia: designing phase IIB trials," Journal of Nutrition, Health and Aging, vol. 15, no. 6, pp. 450-455, 2011.

[22] P. Grumati, L. Coletto, M. Sandri, and P. Bonaldo, "Autophagy induction rescues muscular dystrophy," Autophagy, vol. 7, no. 4, pp. 426-428, 2011.

[23] "Low protein diet in patients with collagen VI related myopathies (LPD)," NCT01438788, 2011, http://clinicaltrials .gov.

[24] F. Gualandi, R. Curci, P. Sabatelli et al., "Macrophages: a minimally invasive tool for monitoring collagen VI myopathies," Muscle and Nerve, vol. 44, no. 1, pp. 80-84, 2011.

[25] F. Gualandi, A. Urciuolo, E. Martoni et al., "Autosomal recessive Bethlem myopathy," Neurology, vol. 73, no. 22, pp. 1883-1891, 2009.

[26] S. Lucioli, B. Giusti, E. Mercuri et al., "Detection of common and private mutations in the COL6A1 gene of patients with Bethlem myopathy," Neurology, vol. 64, no. 11, pp. 1931-1937, 2005.

[27] G. Pepe, B. Giusti, E. Bertini et al., "A heterozygous splice site mutation in COL6A1 leading to an in-frame deletion of the $\alpha 1(\mathrm{VI})$ collagen chain in an Italian family affected by Bethlem myopathy," Biochemical and Biophysical Research Communications, vol. 258, no. 3, pp. 802-807, 1999. 
[28] P. Sabatelli, S. K. Gara, P. Grumati et al., "Expression of the collagen VI $\alpha 5$ and $\alpha 6$ Chains in normal human skin and in skin of patients with collagen VI-related myopathies," Journal of Investigative Dermatology, vol. 131, no. 1, pp. 99-107, 2011.

[29] E. Martoni, A. Urciuolo, P. Sabatelli et al., "Identification and characterization of novel collagen VI non-canonical splicing mutations causing ullrich congenital muscular dystrophy," Human Mutation, vol. 30, no. 5, pp. E662-E672, 2009.

[30] P. Sabatelli, E. Palma, A. Angelin et al., "Critical evaluation of the use of cell cultures for inclusion in clinical trials of patients affected by collagen VI myopathies," Journal of Cellular Physiology, vol. 227, no. 7, pp. 2927-2935, 2012.

[31] R. N. Baumgartner, S. J. Wayne, D. L. Waters, I. Janssen, D. Gallagher, and J. E. Morley, "Sarcopenic obesity predicts instrumental activities of daily living disability in the elderly," Obesity research, vol. 12, no. 12, pp. 1995-2004, 2004.

[32] R. N. Baumgartner, K. M. Koehler, D. Gallagher et al., "Epidemiology of sarcopenia among the elderly in New Mexico," American Journal of Epidemiology, vol. 147, no. 8, pp. 755-763, 1998.

[33] WHO Organization, "Obesity: preventing and managing the global epidemic," Tech. Rep., Geneva, Switzerland, 2000.

[34] A. Coin, G. Sergi, N. Minicuci et al., "Fat-free mass and fat mass reference values by dual-energy X-ray absorptiometry (DEXA) in a 20-80 year-old Italian population," Clinical Nutrition, vol. 27, no. 1, pp. 87-94, 2008.

[35] R. J. O. Van Der Ploeg, V. Fidler, and H. J. G. H. Oosterhuis, "Hand-held myometry: reference values," Journal of Neurology Neurosurgery and Psychiatry, vol. 54, no. 3, pp. 244-247, 1991.

[36] L. Merlini, E. S. Mazzone, A. Solari, and L. Morandi, "Reliability of hand-held dynamometry in spinal muscular atrophy," Muscle and Nerve, vol. 26, no. 1, pp. 64-70, 2002.

[37] L. Merlini, E. Bertini, C. Minetti et al., "Motor function-muscle strength relationship in spinal muscular atrophy," Muscle and Nerve, vol. 29, no. 4, pp. 548-552, 2004.

[38] L. Merlini, A. Solari, G. Vita et al., "Role of gabapentin in spinal muscular atrophy: results of a multicenter, randomized Italian study," Journal of Child Neurology, vol. 18, no. 8, pp. 537-541, 2003.

[39] W. W. Bryan, R. J. Hoagland, J. Murphy et al., "Can we eliminate placebo in ALS clinical trials?" Amyotrophic Lateral Sclerosis and Other Motor Neuron Disorders, vol. 4, no. 1, pp. 11-15, 2003.

[40] E. A. C. Beenakker, J. H. Van der Hoeven, J. M. Fock, and N. M. Maurits, "Reference values of maximum isometric muscle force obtained in 270 children aged 4-16 years by hand-held dynamometry," Neuromuscular Disorders, vol. 11, no. 5, pp. 441-446, 2001.

[41] A. Chetta, A. Zanini, G. Pisi et al., "Reference values for the 6min walk test in healthy subjects $20-50$ years old," Respiratory Medicine, vol. 100, no. 9, pp. 1573-1578, 2006.

[42] Z. Mei, L. M. Grummer-Strawn, A. Pietrobelli, A. Goulding, M. I. Goran, and W. H. Dietz, "Validity of body mass index compared with other body-composition screening indexes for cthe assessment of body fatness in children and adolescents," American Journal of Clinical Nutrition, vol. 75, no. 6, pp. 978-985, 2002.

[43] J. S. Garrow and J. Webster, "Quetelet's index (W/H2) as a measure of fatness," International Journal of Obesity, vol. 9, no. 2, pp. 147-153, 1985.

[44] D. Gallagher, M. Visser, R. E. De Meersman et al., "Appendicular skeletal muscle mass: effects of age, gender, and ethnicity," Journal of Applied Physiology, vol. 83, no. 1, pp. 229-239, 1997.
[45] F. Kanda, Y. Fujii, K. Takahashi, and T. Fujita, "Dual-energy $\mathrm{X}$-ray absorptiometry in neuromuscular diseases," Muscle and Nerve, vol. 17, no. 4, pp. 431-435, 1994.

[46] G. M. Palmieri, T. E. Bertorini, J. W. Griffin, M. Igarashi, and J. G. Karas, "Assessment of whole body composition with dual energy X-ray absorptiometry in Duchenne muscular dystrophy: correlation of lean body mass with muscle function," Muscle Nerve, vol. 19, no. 6, pp. 777-779, 1996.

[47] V. Philippe, L. Pruna, M. Abdel Fattah, V. Pascal, and P. Kaminsky, "Decreased bone mineral density in adult patients with muscular dystrophy," Joint Bone Spine, vol. 78, no. 6, pp. 647654, 2011.

[48] L. Pruna, J. Chatelin, V. Pascal-Vigneron, and P. Kaminsky, "Regional body composition and functional impairment in patients with myotonic dystrophy," Muscle and Nerve, vol. 44, no. 4, pp. 503-508, 2011.

[49] V. Allamand, L. Merlini, and K. Bushby, "166th ENMC International Workshop on Collagen type VI-related Myopathies, 22-24 May 2009, Naarden, The Netherlands," Neuromuscular Disorders, vol. 20, no. 5, pp. 346-354, 2010.

[50] L. J. Hébert, J.-F. Remec, J. Saulnier, C. Vial, and J. Puymirat, "The use of muscle strength assessed with handheld dynamometers as a non-invasive biological marker in myotonic dystrophy type 1 patients: a multicenter study," BMC Musculoskeletal Disorders, vol. 11, article 72, 2010.

[51] M. C. Walter, P. Reilich, S. Thiele et al. et al., "Treatment of dysferlinopathy with deflazacort: a double-blind, placebo-controlled clinical trial," Orphanet Journal of Rare Diseases, vol. 8, no. 1, article 26, 2013.

[52] W. Huygens, M. A. Thomis, M. W. Peeters, R. F. Vlietinck, and G. P. Beunen, "Determinants and upper-limit heritabilities of skeletal muscle mass and strength," Canadian Journal of Applied Physiology, vol. 29, no. 2, pp. 186-200, 2004.

[53] J. D. Cook and D. S. Glass, "Strength evaluation in neuromuscular disease," Neurologic Clinics, vol. 5, no. 1, pp. 101-123, 1987.

[54] B. Camarri, P. R. Eastwood, N. M. Cecins, P. J. Thompson, and S. Jenkins, "Six minute walk distance in healthy subjects aged 5575 years," Respiratory Medicine, vol. 100, no. 4, pp. 658-665, 2006.

[55] T. Troosters, R. Gosselink, and M. Decramer, "Six minute walking distance in healthy elderly subjects," European Respiratory Journal, vol. 14, no. 2, pp. 270-274, 1999.

[56] V. Z. Dourado, M. C. Vidotto, and R. L. F. Guerra, "Reference equations for the performance of healthy adults on field walking tests," Jornal Brasileiro de Pneumologia, vol. 37, no. 5, pp. 607614, 2011. 


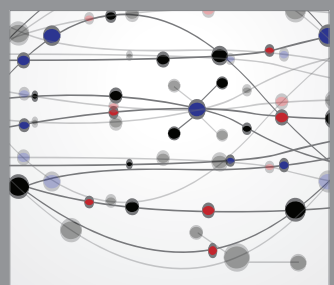

The Scientific World Journal
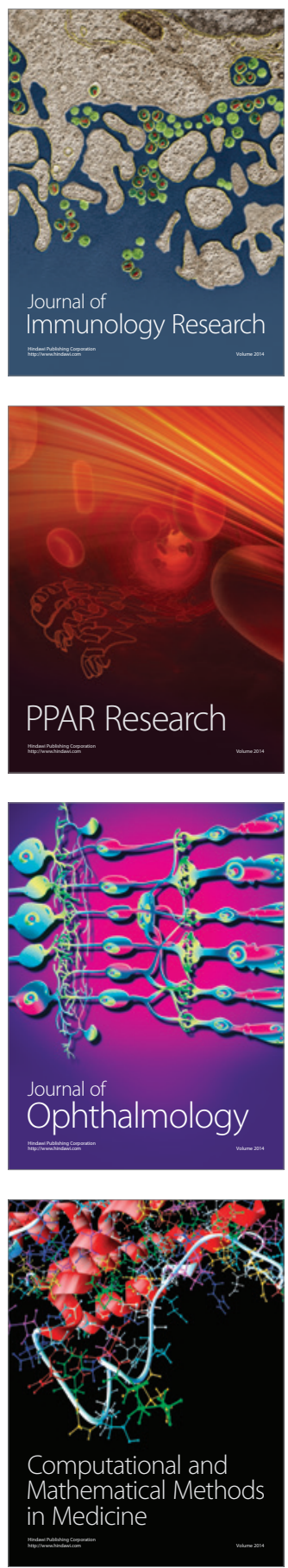

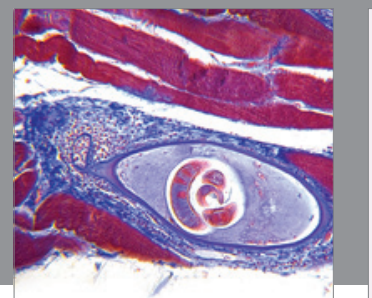

Gastroenterology

Research and Practice
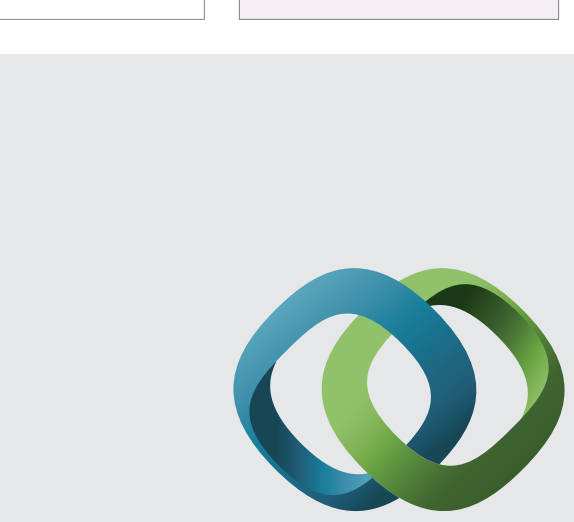

\section{Hindawi}

Submit your manuscripts at

http://www.hindawi.com
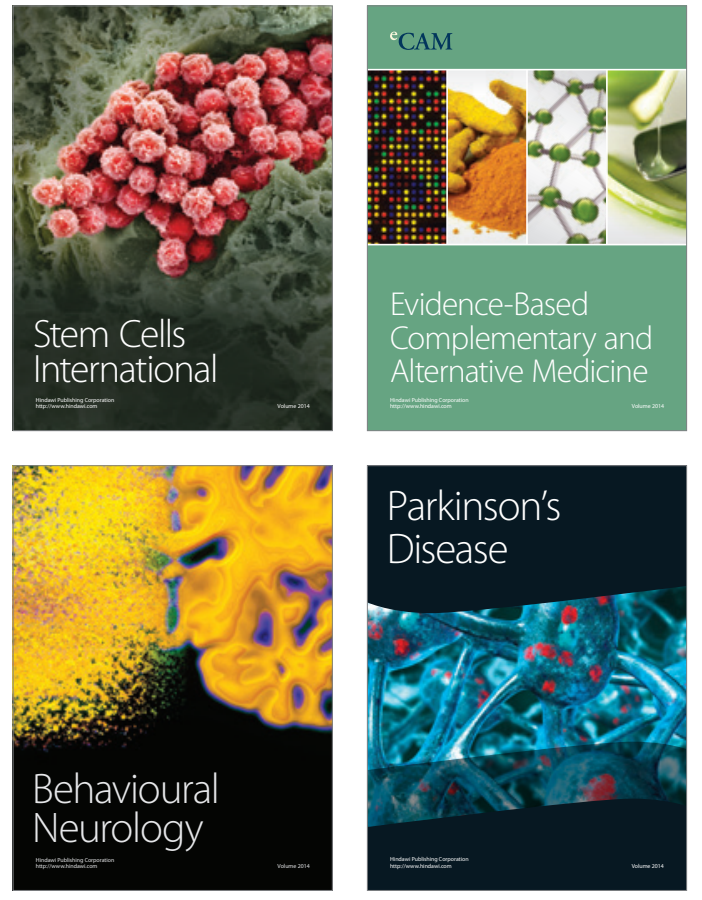
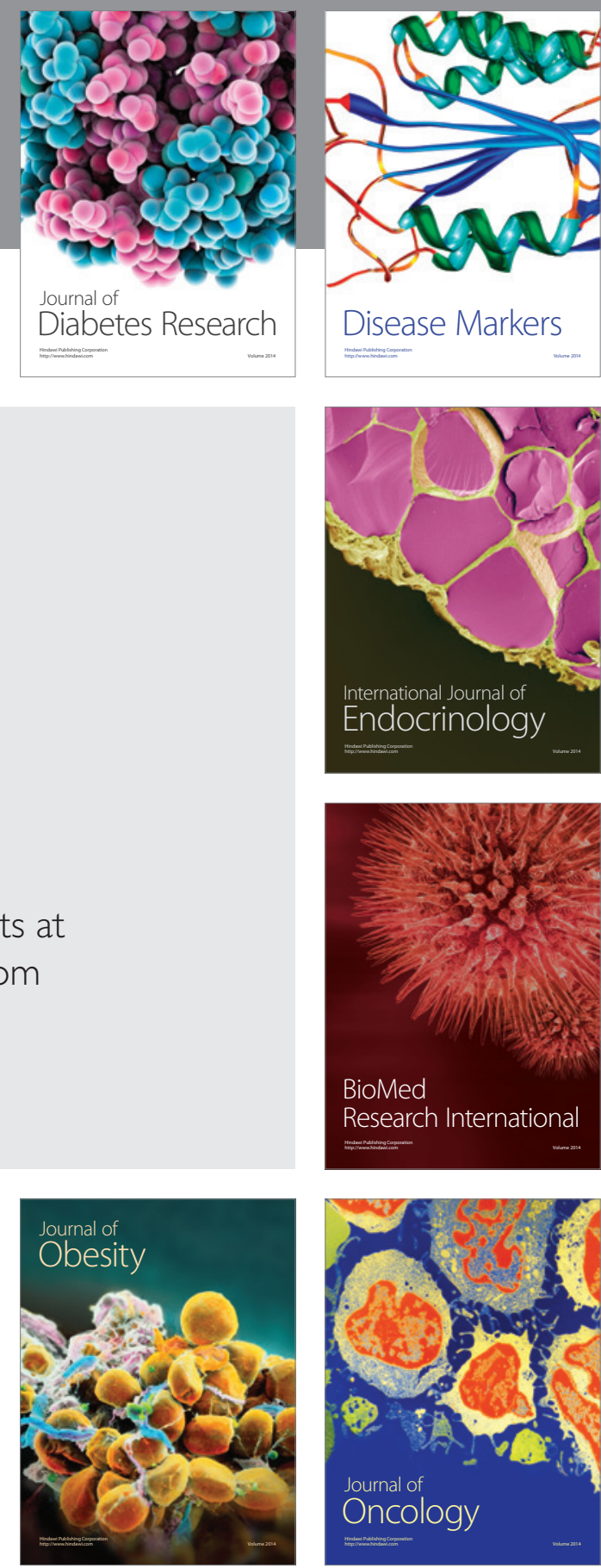

Disease Markers
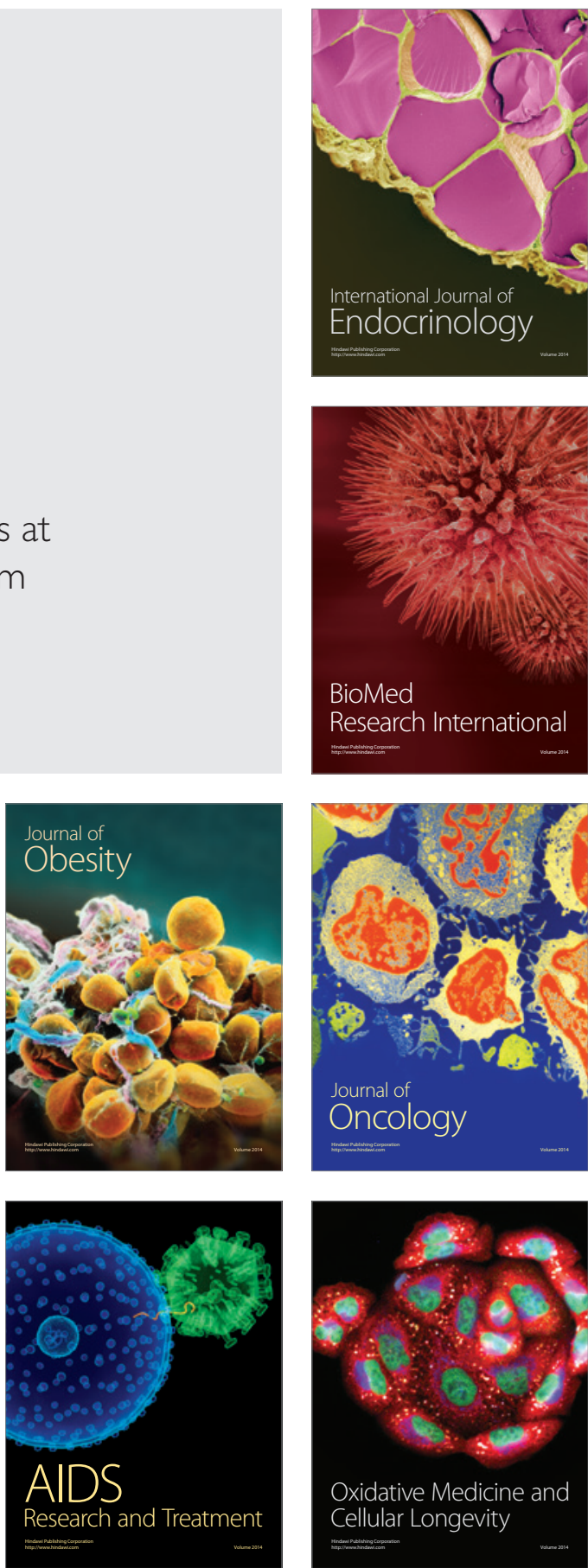